\title{
Analysis of Subsea Energy Supply Systems for Improved Maintenance Using ANFIS and TOPSIS
}

\author{
Chinyere U. Emuchay \\ Offshore Technology Institute, University of Port Harcourt, Nigeria \\ Ogheneruona E. Diemuodeke* \\ Energy and Thermofluid Research Group, Department of Mechanical Engineering \\ University of Port Harcourt, Nigeria \\ Mohammed M. Ojapah \\ Energy and Thermofluid Research Group, Department of Mechanical Engineering \\ University of Port Harcourt, Nigeria
}

The research paper was part of the Nigerian Content Development and Monitoring Board sponsored MSc programme at the Offshore Technology Institute, University of Port Harcourt.

\section{Abstract}

The maintenance plan for the subsea energy supply system during the operation was optimized by firstly training the Adaptive Neuro-Fuzzy Inference System (ANFIS) model with historical data of process variables of the system such as voltage, current, power, and pressure in MATLAB software and then predicting the optimum output of the process using the trained model, which showed a good prediction of operational data after two cycles of computational analysis. The outputs from the trained model, coupled with expert opinions on historical data, were used to develop a Technique for Order of Preference by Similarity to Ideal Solution (TOPSIS) multicriteria algorithm to select the best maintenance strategy. The reliability-centred maintenance, with a performance score of 0.811 , ranked best amongst the maintenance strategies under the studied scenario. The result shows that the procedure could be applied in condition monitoring of operational subsea energy supply systems to predict impending faults through deviation error and prevent failure by the application of an appropriate maintenance strategy.

Keywords: ANFIS, TOPSIS, Maintenance plan, Fault prediction and Subsea power supply systems

DOI: $10.7176 /$ ISDE/12-2-02

Publication date: April $30^{\text {th }} 2021$

\section{Introduction}

The subsea energy supply system is a system that supplies the required power for the operation of subsea equipment, it could be liquid supply in the form of hydraulics, air supply in the form of pneumatics or electric supply in the form of electricity. The systems could be designed to provide a single form of power or it could be a combination of two or more forms. The architecture of a subsea energy supply system depends solely on the design of the subsea control system, which includes all-hydraulic, electro-hydraulic and all-electric system. This supply system includes all equipment concerned with the generation, transmission and distribution of energy to the equipment on the seabed via the production platform e.g. subsea distribution unit, hydraulic power unit, electrical distribution unit, subsea control module, subsea transformers, subsea switch gears, subsea motors etc. (Bai and Bai, 2010).

Detecting faults early before they occur and selecting a cost-effective maintenance strategy is still a difficult task in the offshore oil and gas sector because of the lack of effective tools to handle it, most times faults are attended to after they must have occurred (Altamiranda and Colina, 2007). This equipment has different failure modes that arise when there is a variation in some key electrical and hydraulic parameters such as; voltage, current, frequency, fluid pressure, insulation resistance, flow rate, temperature, critical fluid level, vibration, etc. Hence there is a need to monitor these parameters constantly to detect faults early and ensure the seamless operation of the production system subsea. These faults can cause loss of operability, loss of equipment and potential loss of production all leading to huge profit reduction. Due to the high cost of intervention, maintenance and repair, there is a need to apply a smart and intelligent mechanism such as artificial intelligence (AI) techniques to be able to detect faults before they occur. This could be achieved by monitoring the key energy supply parameters and reduce possible failure to the barest minimum by applying a cost-effective maintenance plan (alternatives against criteria) to reduce the mean time to repair (MTTR) and increase the mean time to failure (MTTF).

Monitoring the key parameters can be achieved using various AI tools such as adaptive neuro-fuzzy inference system or adaptive network-based fuzzy inference system (ANFIS), artificial neural networks (ANN), fuzzy logic (FL), genetic algorithm (GA), Bayesian network, multiple linear regression, support vector machines 
etc. (Altamiranda and Colina, 2007; Solyali, 2020). A Cost-effective maintenance plan can then be selected in a scenario where the fault occurs in the energy supply system using any of the multi-criteria decision-making (MCDM) algorithms such as simple additive weighting (SAW), analytic hierarchal process (AHP), analytic network process (ANP), višekriterijumsko kompromisno rangiranje (VIKOR), and technique for order of preference by similarity to ideal solution (TOPSIS), etc. (Kolios, et al., 2017).

The literature suggests that ANFIS and TOPSIS have been applied in the energy sector, especially the oil and gas, successfully including fault prediction and maintenance schedule, please see Bhowmik (2019); Nieto González and Villanueva (2013); Chang, et al. (2012). However, the ANFIS and TOPSIS work for a maintenance plan is scanty in the field of subsea energy supply systems. The criticality of the energy (power in particular) supply system according to a study carried out by Koto (2017) shows that there has to be a system set in place to ensure minimal downtime of a subsea power system in the production system. However, the literature in the public domain has not adequately addressed the downtime and cost reductions using rigorous, high fidelity and cost-effective solution methods to effectively enhance the subsea power systems performance from the maintenance perspective. In this regard, the major aim of this work is to present a novel approach to improve and simplify the maintenance plan for predictive maintenance and to effectively plan for countermeasures that can be implemented to prevent the failure of subsea energy supply systems.

\section{Introduction}

In this study, an ANFIS-based algorithm will be developed and trained using some historical data of the operation, then tested and validated using another operational data set to produce a model capable of predicting future values with the least possible error. Hence deviation from this forecasted/predicted output signifies a fault in the system and equipment. A maintenance strategy can subsequently be selected based on company standards for maintenance criteria and the severity of the faults to the system to maintain the optimal performance of the system.

For the fault prediction study, the operational data includes the electrical parameters (voltage, current and power) and hydraulic parameters (supply pressure, return pressure and change in pressure) governed by the following equations;

Electrical parameters:

$P=V * I * \operatorname{Cos} \theta$

where $\mathrm{P}$ (watts) is power; $\mathrm{V}$ (volts) is voltage and I (amps) is current.

Hydraulic parameters:

$d P=P_{1}-P_{2}$

where $\mathrm{dP}(\mathrm{kPa})$ is change in pressure; $\mathrm{P}_{1}(\mathrm{kPa})$ is supply pressure and $\mathrm{P}_{2}(\mathrm{kPa})$ is is return pressure.

For the maintenance plan, different maintenance alternatives and criteria were considered as part of the study. The alternatives considered include condition based maintenance (CBM), reliability centred maintenance $(\mathrm{RCM})$, risk based maintenance $(\mathrm{RBM})$, corrective maintenance $(\mathrm{CM})$, predictive maintenance $(\mathrm{PM})$, and routine based maintenance $(\mathrm{RbM})$; while the criteria considered include the cost of maintenance, ageing equipment, safety of the environment, vessel availability, personnel utilization, personnel safety, reliability of strategy. These alternatives and criteria were selected from Shafiee (2015) and consultation with industry experts on the strategies and factors considered when planning for maintenance.

\subsection{Adaptive Neuro-Fuzzy Inference System (ANFIS)}

The ANFIS system combines the ability of two methods; the fuzzy inference system (FIS) using fuzzy logic and the neural network system. This setup helps to reduce the shortfalls of the individual methods and enhance their advantages. The fuzzy inference system which is good in handling vague or unclear problems converts the input to output by passing it through the fuzzification, inference and defuzzification layer. The inference layer uses expert knowledge or previous experience of the system to form IF - THEN rules and adjust the rules using the set of data to infer a near accurate result during the computation. The artificial neural network (ANN) is a model that is designed to replicate the human neurons, to perform activities similar to the human brain (Alavala, 2008). Neural network structure consists of neurons that are separated into three (3) or more layers - input layer, hidden layer (black box) and the output layer. During the model computation, weights, bias and activation function (sigmoid or tanh function) are considered and used for the computation. Figures 1 and 2 shows the different layers of the FIS and ANN system. 


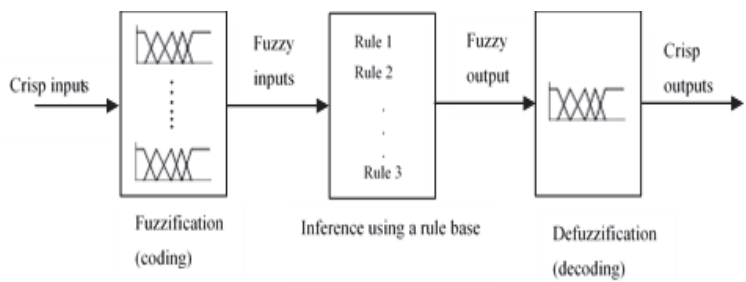

Figure 1: Fuzzy Inference system

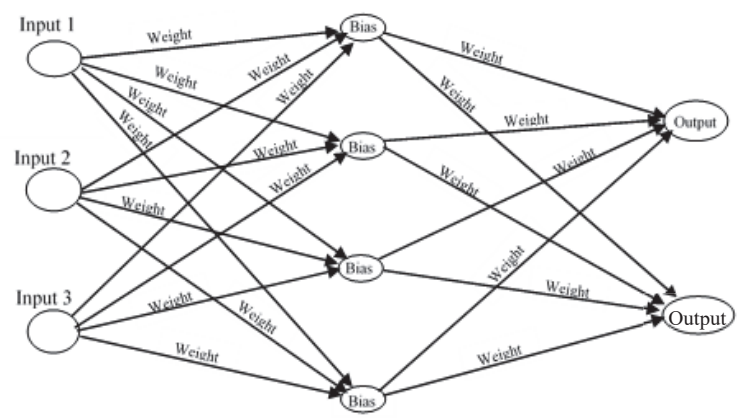

Figure 2: Artificial neural network

ANN and FIS offer similarities and advantages such as (Alavala, 2008):

- They are both designed to work without a mathematical model.

- They can be applied to non-linear and dynamic systems.

- They can predict outcomes from a set of data.

Despite the similarities and advantages ANN and FIS offer they have the following disadvantages (Alavala, 2008):

- For FIS, there is difficulty in developing the rules, experts opinions differ from person to person, requires a lot of experience and includes bias in judgement

- For ANN, there is a possibility of overtraining the black box which can lead to overfitting, requires a lot of computational power, and there is no known way to determine the number of neurons and hidden layers.

Hence there is a need to harness mainly their advantages using ANFIS. Jang, et al. (1997) developed another tool that combines the advantages of FIS and ANN to form the ANFIS tool, which is also known as a universal estimator due to its ability to solve a very large number of problems (complex and non-linear problems). It combines the rule-based fuzzy manipulation (IF-THEN rules) with the learning ability of neural networks. The FIS model adopted in this study is the Sugeno-type due to its simplicity and accuracy (Ahmed and Shah, 2017).

The following are the different layers an ANFIS model uses to predict accurately:

- Layer 1: This layer is an adaptive node. Here the input function is defined, as shown in Equations (3) and (4).

$$
\begin{array}{ll}
\mathrm{O}_{i}^{1}=\mu_{\mathrm{A}_{i}}(x) & \text { for } i=1,2 \\
\mathrm{O}_{i}^{1}=\mu_{\mathrm{B}_{i}}(y) & \text { for } i=1,2
\end{array}
$$

- Layer 2: The layer is fixed node (circle) and consists of an AND operation (minimum). The output is the product of the input membership functions which connotes the rule's firing strength as seen in Equation (5). It is represented with $\Pi$ symbol.

$$
\mathrm{O}_{i}^{2}=\mathrm{W}_{1}=\mu_{\mathrm{A}_{i}}(x) \mu_{\mathrm{B}_{i}}(y)
$$

- Layer 3: The layer is made of fixed (circle) nodes and the output is the normalized firing strength of each rule i.e. the ratio of a particular firing strength to the sum of all firing strengths as seen in Equation (6). N symbol is used to represent the nodes in this layer.

$$
\mathrm{O}_{i}^{3}=\overline{\mathrm{W}_{i}}=\frac{\mathrm{W}_{i}}{\mathrm{~W}_{1}+\mathrm{W}_{2}} \quad \text { for } i=1,2
$$

- Layer 4: This layer is composed of an adaptive (square) node. It is made up of the normalized firing strength and the resultant parameter $f_{1}$ as seen in Equation (7).

$\mathrm{O}_{i}^{4}=\overline{\mathrm{W}}_{i} f_{i}=\overline{\mathrm{W}}_{i}\left(p_{1} x+q_{1} y+r_{1}\right)$

- Layer 5: This consist of a single fixed node. It represents the sum of all output signals of layer 4 as seen in Equation (8). 


$$
\mathrm{O}_{i}^{5}=\sum_{i} \overline{\mathrm{W}_{i}} f_{i}=\frac{\sum_{i} \mathrm{~W}_{i} f_{i}}{\sum_{i} \mathrm{~W}_{i}}
$$

Figure 3 shows how the five different layers make up the ANFIS tool.

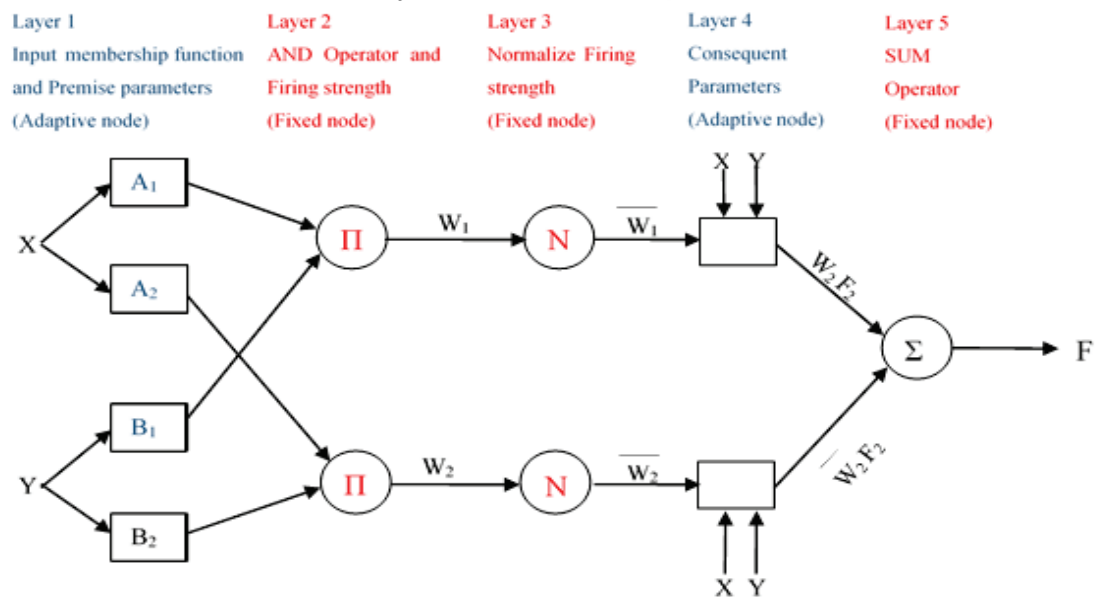

Figure 3: Simplified Sugeno ANFIS structure for two inputs

ANFIS model will help to handle the uncertainties and errors such as losses (transmission and distribution losses) and harmonic distortion using its FIS structure and learn the data structure to generate rules to expertly predict fault conditions on operational data.

\subsubsection{ANFIS in MATLAB}

MATLAB is used to carry out these computations easily because of its simplicity. The data set is divided into 3 groups; $70 \%$ training data, 15\% testing data, 15\% Checking data. The ANFIS editor has four (4)

parts:

i. Data loading

ii. $\quad$ FIS generation (the fuzzy logic part)

iii. Learning method (the neural network part)

iv. Testing and plotting (i.e. ANFIS o/p vs. Training/testing/checking data).

Figure 4 shows the flowchart of using the ANFIS model to predict failure;

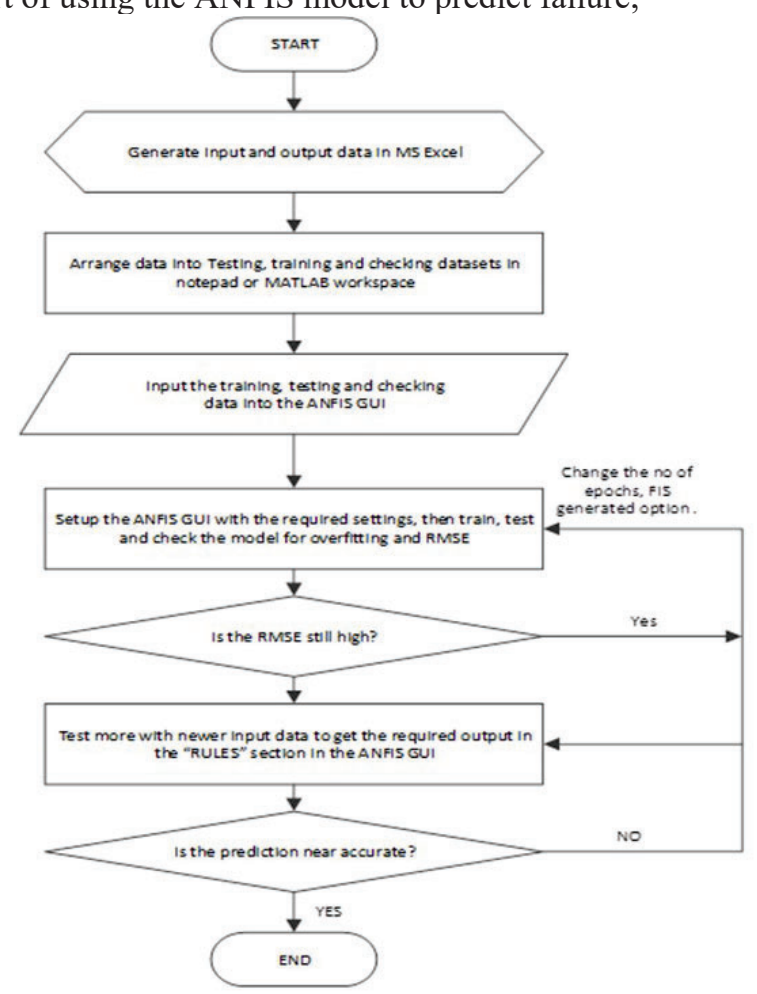

Figure 4: ANFIS model generation flowchart 


\subsection{Technique for Order of Preference by Similarity to Ideal Solution (TOPSIS)}

The TOPSIS system which is part of the MCDM is developed to handle the selection of the right maintenance strategy which will help prevent any potential failure of the system. The TOPSIS system was selected for its simplicity and directness; it bases its ideology on the fact that the best alternative in every scenario is one that has the smallest Euclidean distance from the positive ideal solution (PIS) and the largest distance from the negative ideal solution (NIS). The positive ideal solution is values that signify the good attributes of criteria and the negative ideal solution signifies are the worst attributes of criteria. It is should also be noted that this does not mean the lowest value is the worst attribute and the highest value is the best attribute because, in some criteria, it can be the other way e.g. In terms of cost of maintenance, the lowest cost is the best attribute and a low value for the reliability of a strategy is the worst attribute. The following are steps involved in developing a TOPSIS system (Umofia, 2014; Yavuz, 2012, Ukoba et al., 2020):

i. Understand the scenario

ii. Develop a system highlighting the alternatives and criteria at that point.

iii. Gather expert opinions on the weight of each criterion to the process.

iv. Convert all linguistic terms to values.

v. Develop your model using the various computational steps.

vi. Use the developed model to select the best alternative to be implemented.

vii. Implement the decision and prevent failure.

The various computational steps that can effectively select the best $\mathrm{i}^{\text {th }}$ criterion include (Ukoba et al., 2020):

i. $\quad$ Development of the decision matrix using Equation (9);

$$
X=\left[X_{i j}\right]
$$

ii. $\quad$ Normalize each value in the decision matrix using Equation (10);

$$
r_{i j}=\frac{x_{i j}}{\sqrt{\sum_{i=1}^{m} X_{i j}^{2}}}
$$

iii. Develop the weighted normalized decision matrix for a set of weights $\mathrm{W}$ ranging from $\mathrm{W}_{1}$ to $\mathrm{W}_{\mathrm{n}} \mathrm{using}$ Equation (11);

$$
V=R W ; \quad \text { where } W=\sum_{j=1}^{n} W_{j}=1 \text { and } R=\left[r_{i j}\right]
$$

iv. Get the ideal best $\mathrm{A}^{+}$and ideal worst value $\mathrm{A}^{-}$using Equations (12) and (13);

$\mathrm{A}^{+}=\left\{\left(\max _{i} v_{i j} \mid j \in J\right),\left(\min _{i} v_{i j} \mid j \in J^{\prime}\right), \mathrm{i}=1,2,3, \ldots, \mathrm{m}\right\}=\left\{\mathrm{V}_{1}^{+}, \mathrm{V}_{2}^{+}, \ldots, \mathrm{V}_{\mathrm{n}}^{+}\right\}$

$\mathrm{A}^{-}=\left\{\left(\min _{i} v_{i j} \mid j \in J\right),\left(\max _{i} v_{i j} \mid j \in J^{\prime}\right), \mathrm{i}=1,2,3, \ldots, \mathrm{m}\right\}=\left\{\mathrm{V}_{1^{-}}, \mathrm{V}_{2}^{-}, \ldots, \mathrm{V}_{\mathrm{n}}^{-}\right\}$

where $\mathbf{J}=\{\mathrm{j}=1,2,3 \ldots \mathrm{n}$ and $\mathrm{j}$ represents the benefit criteria $\}$

$J^{\prime}=\{\mathrm{j}=1,2,3 \ldots \mathrm{n}$ and $\mathrm{j}$ represents the cost criteria $\}$

This show that $\mathrm{A}^{+}$represent value with the maximum benefit and lowest cost (ideal best solution) and $\mathrm{A}^{-}$represent the value with the minimum benefit and largest cost (ideal worst solution).

v. Get the euclidean distance from the positive ideal best solution and negative ideal worst solution using Equations (14) and (15).

$$
\begin{array}{ll}
S_{i}^{+}=\left[\sum_{j=1}^{m}\left(V_{i j}-V_{j}^{+}\right)^{2}\right]^{0.5} & ; \text { for } i=1,2,3, \ldots, m \\
S_{i}^{-}=\left[\sum_{j=1}^{m}\left(V_{i j}-V_{j}^{-}\right)^{2}\right]^{0.5} & ; \text { for } i=1,2,3, \ldots, m
\end{array}
$$

vi. Calculate the performance score for the Euclidean distance from the positive ideal best solution and negative ideal worst solution, i.e. closeness to the ideal solution using Equation (16).

$$
P_{i}=\frac{s_{i}^{-}}{S_{i}^{+}+S_{i}^{-}} \quad \text { where } 0 \leq P_{i} \leq 1 \text {; for } i=1,2,3, \ldots, m
$$

vii. Rank alternatives based on the performance score. The highest performance score $\left(P_{i}\right)$ gets the highest rank.

Figure 5 shows the flowchart describing the process of the TOPSIS algorithm. 


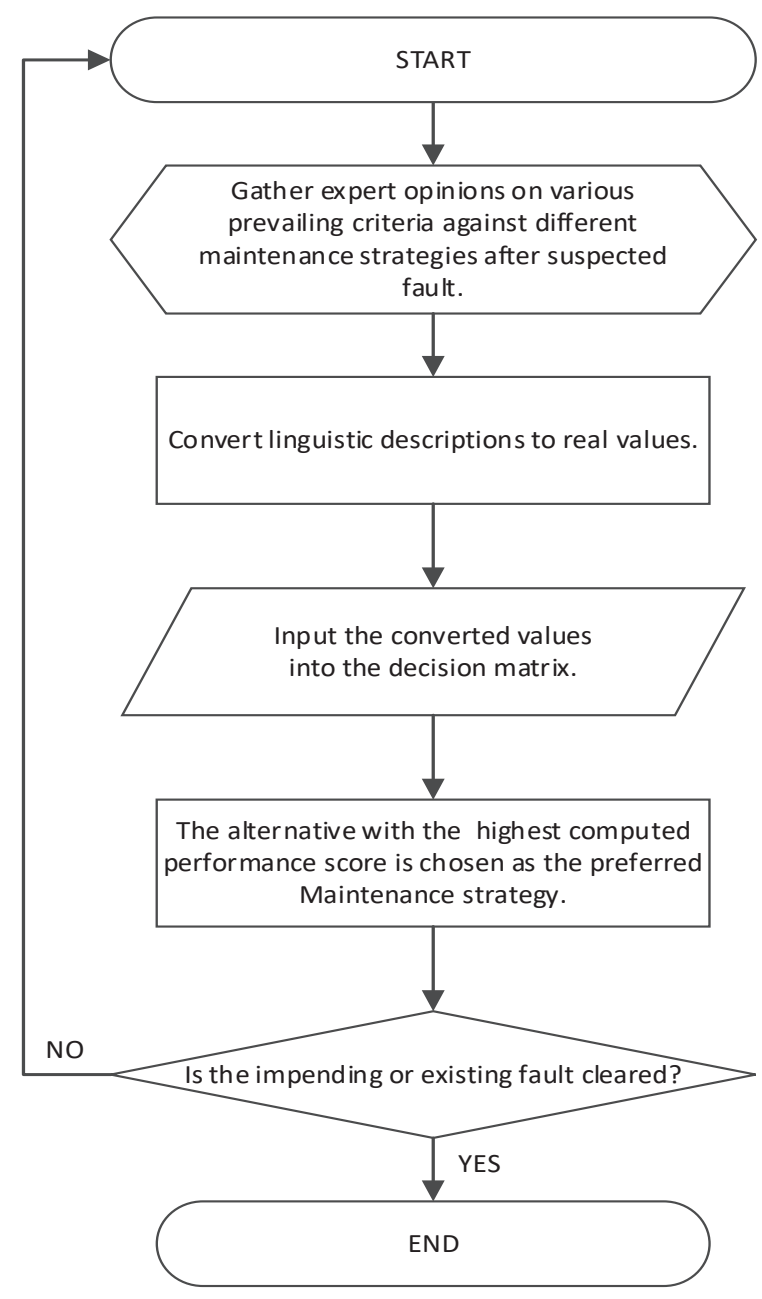

Figure 5: TOPSIS model generation

\subsection{Data Collection}

A questionnaire was developed and filled by professionals who include; Subsea Engineer, Technical Managers, Project Engineer and Engineering Managers with over 5 years of experience in the oil and gas sector including experience in subsea activities.

The following are the data ranges gathered from the response to the questionnaire;

- The voltage range from the questionnaire: $460-480 \mathrm{~V}$

- The current range from the questionnaire: $225-245 \mathrm{amps}$

- The supply pressure from the questionnaire: $68947.57-103421.355 \mathrm{kPa}$

- The pressure drop from an oral interview with experts: $17236.8925-31026.4065 \mathrm{kPa}$

100 data points were populated using Microsoft Excel and a power factor $(\cos \theta)$ of 0.85 was assumed for the electrical power system that highlights the losses in the system and applied to Equation (1).

The linguistic values were used in the questionnaire by the experts to describe an alternative against the corresponding criteria and hence develop a matrix. The linguistic variable was then converted to values to enable further computation of the ideal best solution. Using expert judgement and literature review, a weight of 0.16 was assigned to the cost of maintenance, personnel safety and safety of the environment while the other criteria were assigned a weight of 0.13 . Figure 6 gives a general overview of this work; from detecting possible fault to selecting the best maintenance strategy to be applied for the situation considering the present conditions of operation which may depend on economic and technical factors. 


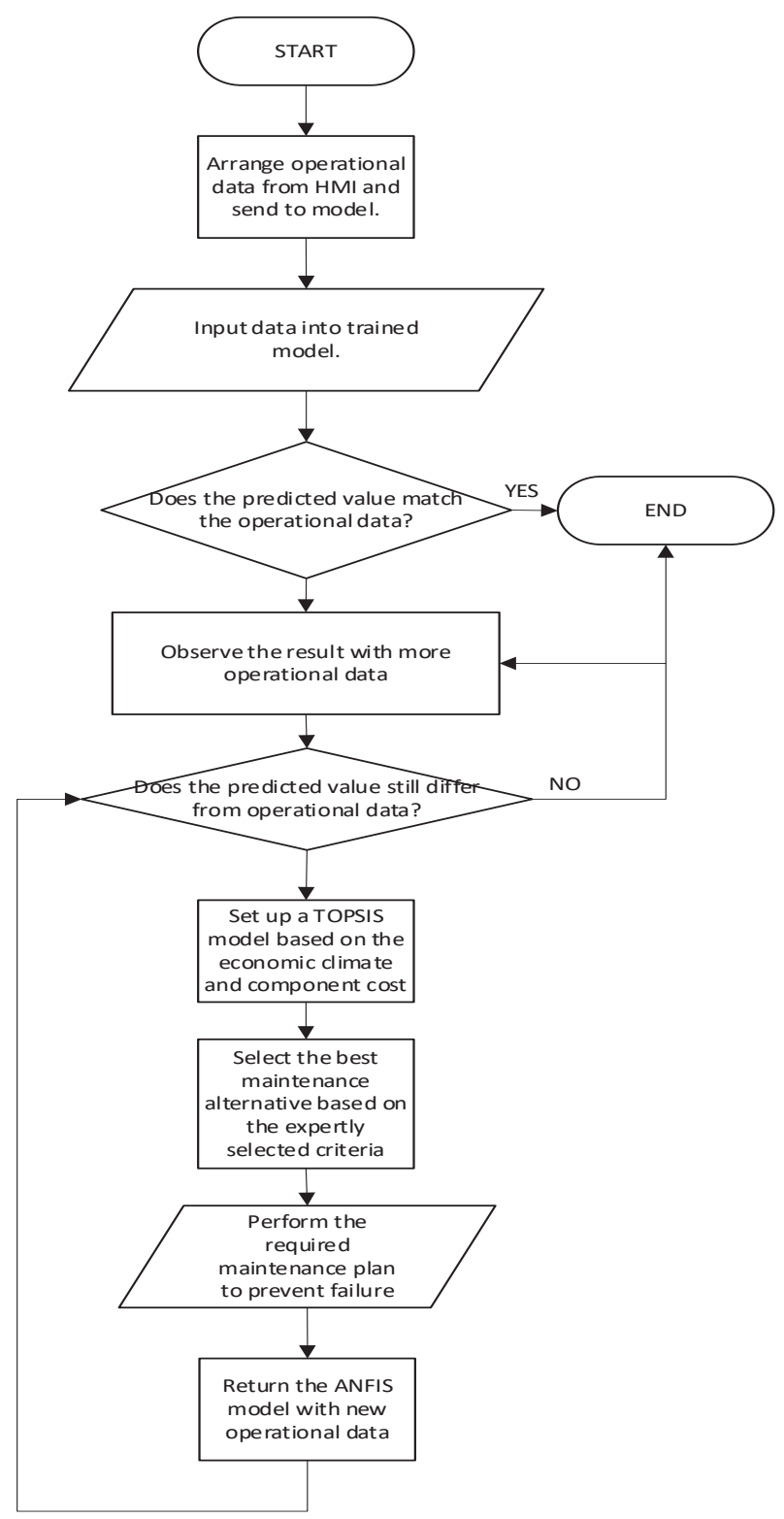

Figure 6: Improved maintenance using ANFIS and TOPSIS

\section{Results and Discussion}

\subsection{Results from ANFIS}

Equations (3) - (8) is applied by the MATLAB to obtain the desired output value after the following processes:

- Training, testing and checking data loading to the ANFIS editor.

- FIS generation using grid partition.

- Learning process using hybrid optimization method and 20 epoch's (model finished training at epoch 2).

- Plotting ANFIS output against training, testing and checking data as seen in Figure 7. 


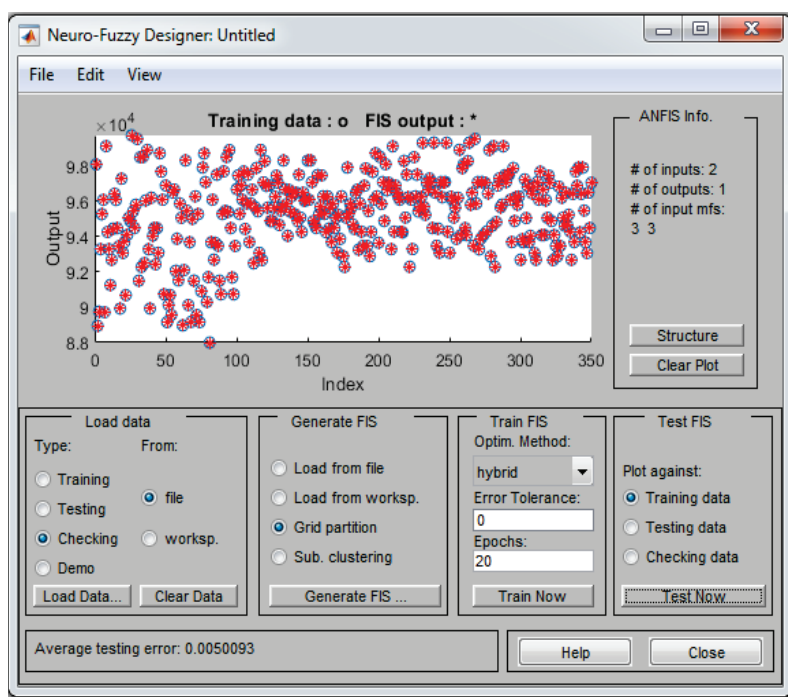

Figure 7: Testing FIS model output vs Training Data

The root mean square error (RMSE) of the training, testing and checking data for the electrical and hydraulic values can be seen in Figures 8 and 9. These low RMSE values for the different data set shows that the trained ANFIS model has high accuracy in predicting output values when given operational data sets. The errors seen differ from the training phase to testing and the checking phase for different data sets. This shows that the model's learning ability depends on the quality and quantity of data supplied to it.

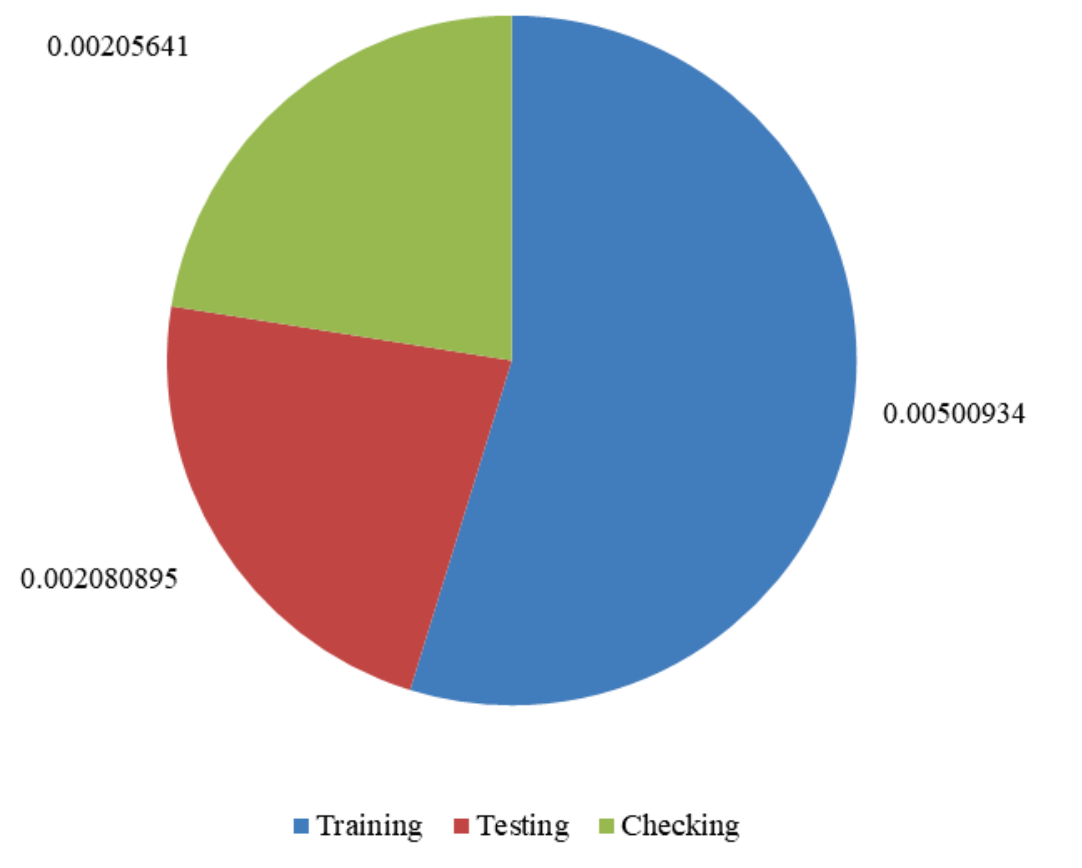

Figure 8: Electrical values RMSE 


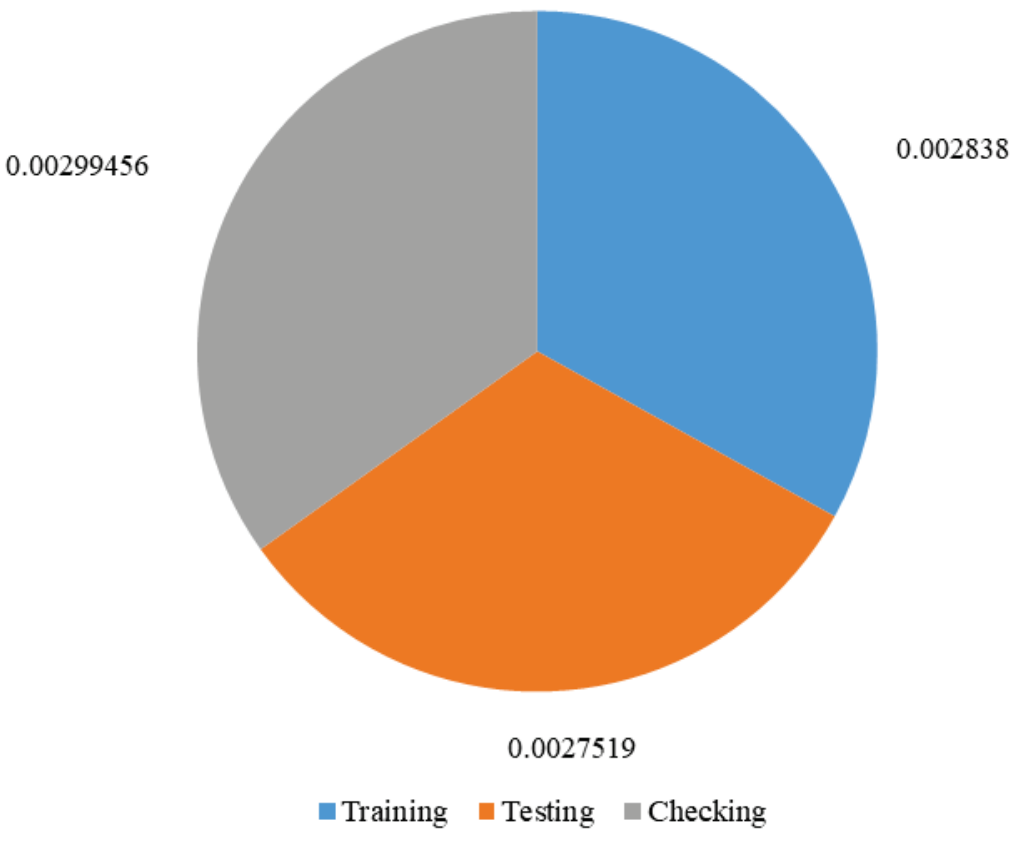

Figure 9: Hydraulic raw data RMSE

Figure 10 shows the rule viewer of the model which shows that 9 rules were formed from the data set using the triangular membership function.

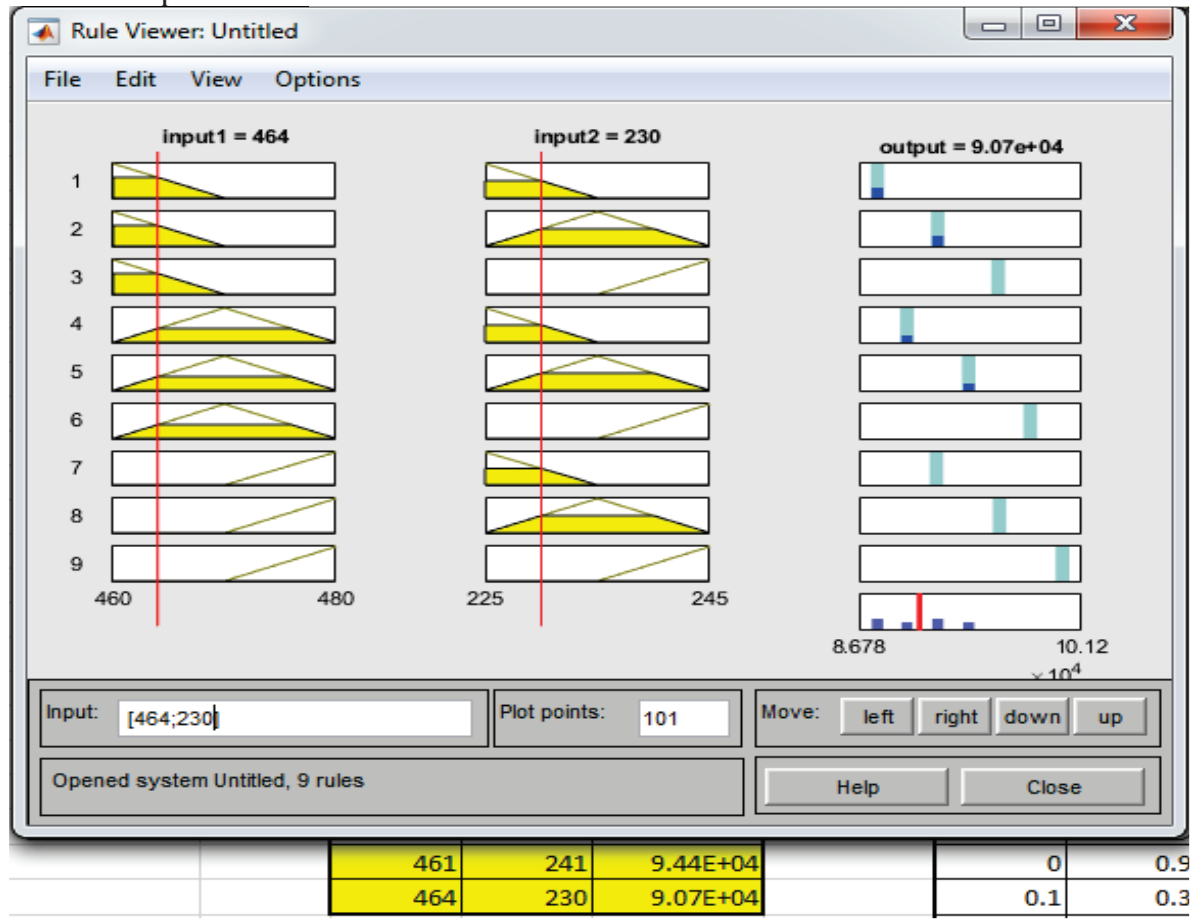

Figure 10: Rule viewer for ANFIS model testing 464V and 230A

Figure 11 and 12 highlights a graphical representation of the ANFIS output performance against another set of measured data. 


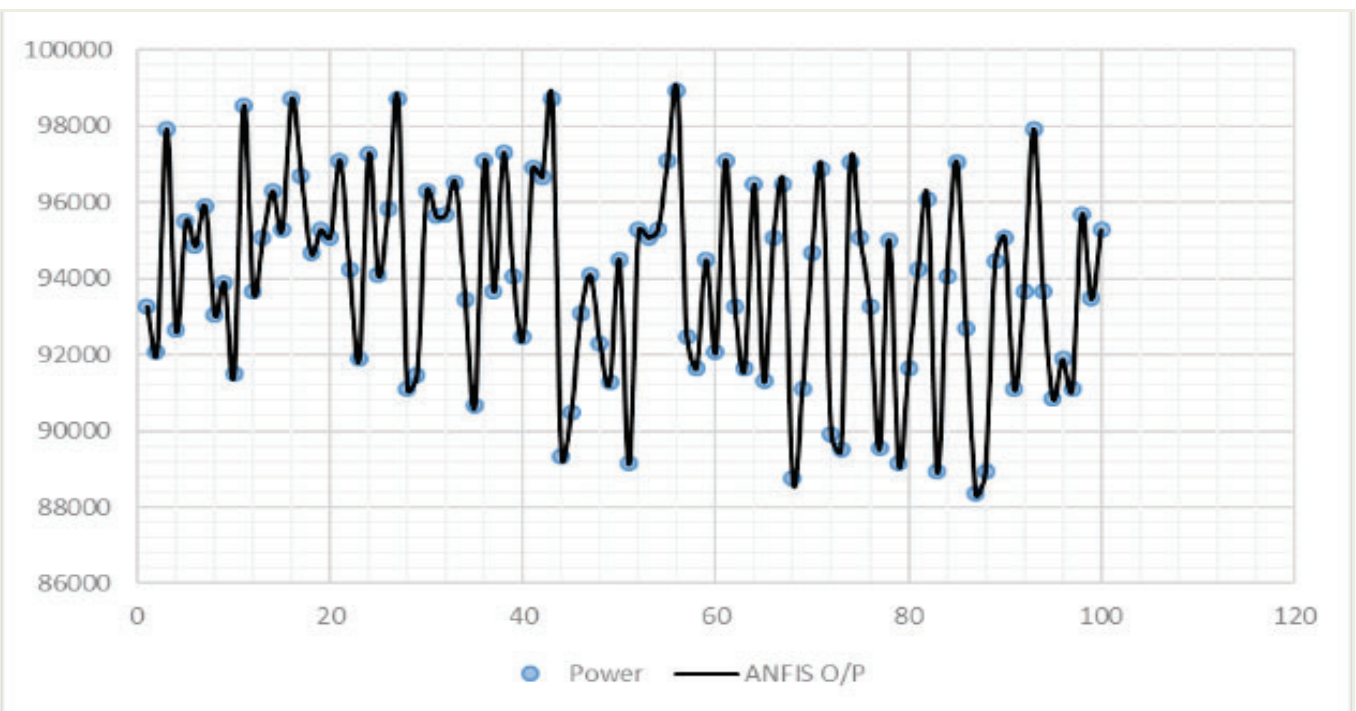

Figure 11: ANFIS predicted output vs electrical measured data

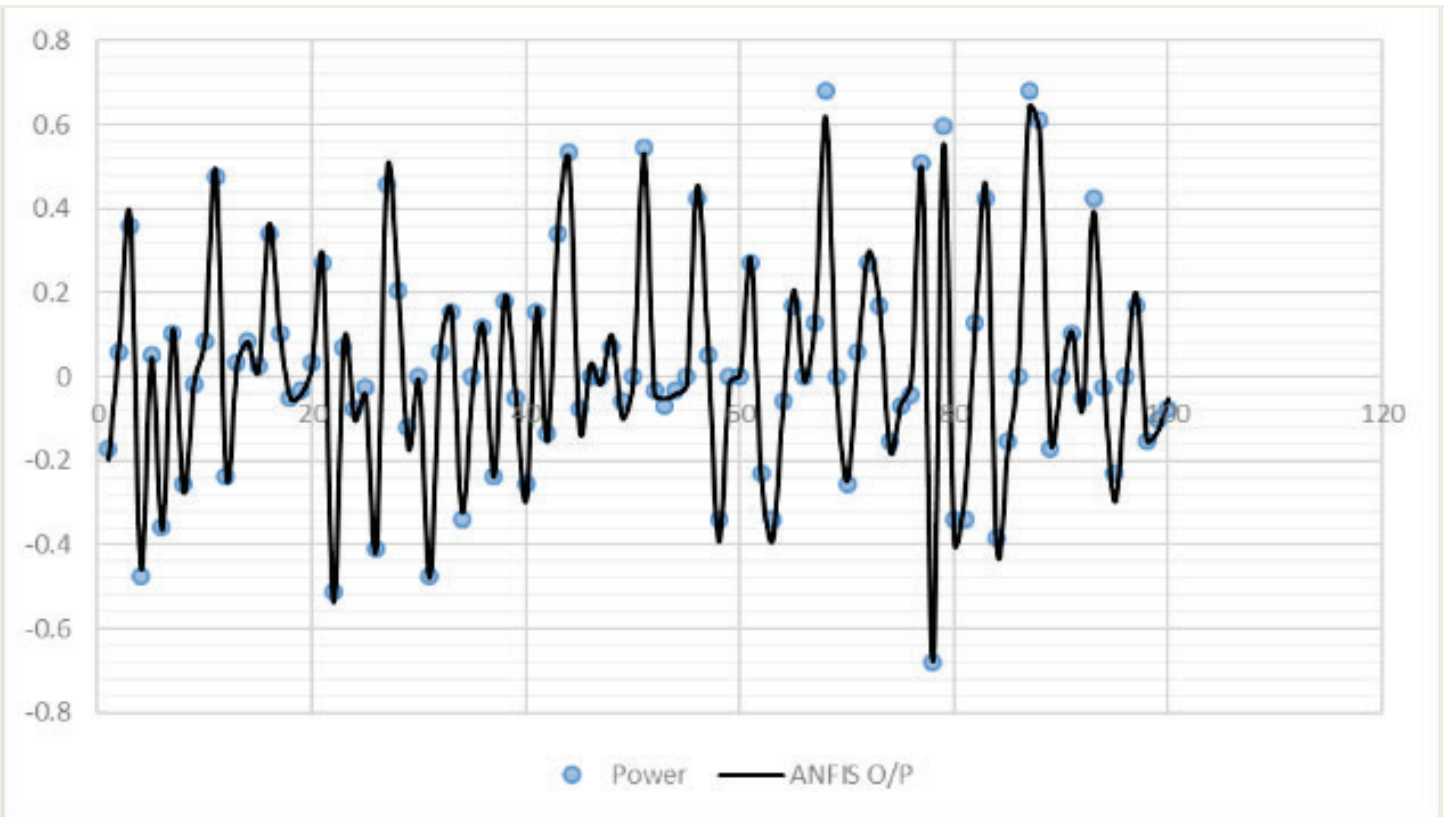

Figure 12: ANFIS predicted output vs hydraulic measured data

\subsection{Results from TOPSIS}

MS Excel 2016 was used to generate Tables 1 - 5 for the calculation of the ideal best solution using the Euclidean distance concept of the TOPSIS. Table 1 shows the type and weight of each of the criteria $i$ used in the computation.

Table 1: Properties of the Criteria

\begin{tabular}{lllc}
\hline $\boldsymbol{i}$ & Criteria & Type & Weight \\
\hline 1 & Cost of maintenance & Negative (-) & 0.16 \\
2 & Aging equipment & Positive (+) & 0.13 \\
3 & Safety of environment & Positive (+) & 0.16 \\
4 & Vessel availability & Positive (+) & 0.13 \\
5 & Personnel utilization & Positive (+) & 0.13 \\
6 & Personnel Safety & Positive (+) & 0.16 \\
7 & Reliability of strategy & Positive (+) & 0.13 \\
\hline
\end{tabular}

Linguistic matrix was developed using expert opinions and converted to decision matrix as seen in Table 2, using Equation (3). The following representations was used to convert the linguistic matrix - excellent $=5$; very $\operatorname{good}=4 ; \operatorname{good}=3$; poor $=2$; and very poor $=1$. 
Table 2: Decision matrix

\begin{tabular}{ccccccccc}
\hline \multirow{2}{*}{ Criterial } & \multirow{2}{*}{ Type } & \multicolumn{10}{c}{ Alternatives } \\
\cline { 3 - 9 } & & CBM & RCM & RBM & CM & PM & RbM & Weight \\
\hline 1 & $(-)$ & 5 & 4 & 3 & 5 & 4 & 3 & 0.16 \\
2 & $(+)$ & 2 & 4 & 4 & 2 & 4 & 1 & 0.13 \\
3 & $(+)$ & 1 & 4 & 5 & 2 & 4 & 3 & 0.16 \\
4 & $(+)$ & 4 & 5 & 4 & 1 & 5 & 4 & 0.13 \\
5 & $(+)$ & 4 & 3 & 3 & 4 & 2 & 4 & 0.13 \\
6 & $(+)$ & 3 & 5 & 5 & 2 & 4 & 3 & 0.16 \\
7 & $(+)$ & 1 & 5 & 4 & 2 & 4 & 2 & 0.13 \\
\hline
\end{tabular}

Equation (10) is then used to normalize the decision matrix to obtain Table 3.

Table 3: Normalized decision matrix

\begin{tabular}{cccccccc}
\hline \multirow{2}{*}{ Criterial Type } & \multicolumn{7}{c}{ Alternatives } \\
\cline { 2 - 7 } & & CBM & RCM & RBM & CM & PM & RbM \\
\hline 1 & $(-)$ & 0.5 & 0.4 & 0.3 & 0.5 & 0.4 & 0.3 \\
2 & $(+)$ & 0.265 & 0.529 & 0.529 & 2 & 4 & 1 \\
3 & $(+)$ & 0.119 & 0.475 & 0.593 & 2 & 4 & 3 \\
4 & $(+)$ & 0.402 & 0.503 & 0.402 & 1 & 5 & 4 \\
5 & $(+)$ & 0.478 & 0.359 & 0.359 & 4 & 2 & 4 \\
6 & $(+)$ & 0.319 & 0.533 & 0.533 & 2 & 4 & 3 \\
7 & $(+)$ & 0.123 & 0.615 & 0.492 & 2 & 4 & 2 \\
\hline
\end{tabular}

Equation (11) is used to find the weighted normalized decision matrix, while Equations (12) and (13) are used to calculate the ideal worse and ideal best values to obtain Table.4. Subsequently, using Equations (14) and (15) the Euclidean distance from the ideal best and ideal worst values are calculated for each alternative considering all the criteria, this allows the ranking to be obtained.

Table 4: Weighted normalized decision matrix with ideal best, ideal worst values and Euclidean distance.

\begin{tabular}{llcccccccc}
\hline \multirow{2}{*}{ Criterial } & \multirow{2}{*}{ Type } & \multicolumn{9}{c}{ Alternatives } \\
\cline { 3 - 11 } & & CBM & RCM & RBM & CM & PM & RbM & $V_{j}^{+}$ & $V^{-}$ \\
\hline 1 & $(-)$ & 0.08 & 0.064 & 0.048 & 0.08 & 0.064 & 0.048 & $\mathbf{0 . 0 8}$ & $\mathbf{0 . 0 4 8}$ \\
2 & $(+)$ & 0.034 & 0.069 & 0.069 & 0.034 & 0.069 & 0.017 & $\mathbf{0 . 0 6 9}$ & $\mathbf{0 . 0 1 7}$ \\
3 & $(+)$ & 0.019 & 0.076 & 0.095 & 0.038 & 0.076 & 0.057 & $\mathbf{0 . 0 9 5}$ & $\mathbf{0 . 0 1 9}$ \\
4 & $(+)$ & 0.052 & 0.065 & 0.052 & 0.013 & 0.065 & 0.052 & $\mathbf{0 . 0 6 5}$ & $\mathbf{0 . 0 1 3}$ \\
5 & $(+)$ & 0.062 & 0.047 & 0.047 & 0.062 & 0.031 & 0.062 & $\mathbf{0 . 0 6 2}$ & $\mathbf{0 . 0 3 1}$ \\
6 & $(+)$ & 0.051 & 0.085 & 0.085 & 0.034 & 0.068 & 0.051 & $\mathbf{0 . 0 8 5}$ & $\mathbf{0 . 0 3 4}$ \\
7 & $(+)$ & 0.016 & 0.08 & 0.064 & 0.032 & 0.064 & 0.032 & $\mathbf{0 . 0 8}$ & $\mathbf{0 . 0 2}$ \\
\hline & $\mathbf{S}_{i}^{+}$ & $\mathbf{0 . 1 1 1}$ & $\mathbf{0 . 0 2 9}$ & $\mathbf{0 . 0 4 1}$ & $\mathbf{0 . 1 0 9}$ & $\mathbf{0 . 0 4 6}$ & $\mathbf{0 . 0 9 4}$ & &
\end{tabular}

Applying Equation (16) on Table 4 one obtains Table 5, this shows that the Reliability Centered Maintenance (RCM) is the ideal best solution because the performance score of 0.811 represents the closest to the ideal solution of 1.0 amongst other alternatives.

Table 5: Euclidean distance, Performance score and Rank

\begin{tabular}{lcccccc}
\hline & \multicolumn{7}{c}{ Alternatives } \\
\cline { 2 - 7 } & CBM & RCM & RBM & CM & PM & RbM \\
\hline $\mathbf{S}_{\mathbf{i}}^{+}$ & 0.111 & 0.029 & 0.041 & 0.109 & 0.046 & 0.093 \\
$\mathbf{S}_{\mathbf{i}^{-}}$ & 0.064 & 0.126 & 0.123 & 0.054 & 0.111 & 0.067 \\
$\mathbf{S}_{\mathbf{i}}^{+}+\mathbf{S}_{\mathbf{i}}^{-}$ & 0.175 & 0.155 & 0.164 & 0.164 & 0.157 & 0.161 \\
$\mathbf{P}_{\mathbf{i}}$ & 0.366 & $\mathbf{0 . 8 1 1}$ & 0.749 & 0.329 & 0.706 & 0.417 \\
Rank & $5^{\text {th }}$ & $1^{\text {st }}$ & $2^{\text {nd }}$ & $6^{\text {th }}$ & $3^{\text {rd }}$ & $4^{\text {th }}$ \\
\hline
\end{tabular}

The TOPSIS results show that for this studied scenario, RCM will be employed any time subsea power equipment starts deviating from its desired values. The consequence of that equipment failing should first be considered before issuance of maintenance approval, this will thus save cost.

\section{Conclusion}

This paper shows that condition monitoring to predict impending faults on subsea power supply systems can be achieved by using available historical operation data such as voltage, current, power and pressure to train an ANFIS model. Then use the trained ANFIS model to predict what the future measured values will be, given input values of the key monitored parameters. When the predicted values from the ANFIS model varies beyond 
an acceptable range from the measured output values, a TOPSIS algorithm was used to select the best maintenance plan to employ to prevent failure of the system. This has the potential for huge cost savings for companies and reduces downtime. The outputs from the trained model, coupled with expert opinions on historical data, were used to develop a Technique for Order of Preference by Similarity to Ideal Solution (TOPSIS) multi-criteria algorithm to select the best maintenance strategy. The reliability-centred maintenance, out of the five maintenance strategies, with a performance score of 0.811 , ranked best amongst the maintenance strategies under the studied scenario. The result shows that the procedure could be applied in condition monitoring of operational subsea energy supply systems to predict impending faults through deviation error and prevent failure by the application of an appropriate maintenance strategy. This procedure would play a major role in implementing fault type detection and fault location features.

\section{Reference}

Ahmed, A. A. M., and Shah, S. M. A. (2017). Application of adaptive neuro-fuzzy inference system (ANFIS) to estimate the biochemical oxygen demand (BOD) of Surma river. Journal of King Saud University Engineering Sciences, 29(3), 237-243. https://doi.org/10.1016/j.jksues.2015.02.001

Alavala, C. R. (2008). Fuzzy logic and neural networks: basic concepts and applications. New Delhi, India: New Age.

Altamiranda, E., and Colina, E. (2007). Intelligent subsea control. Computing and Control Engineering, 18(4), 40-44. https://doi.org/10.1049/cce:20070406

Bai, Y., and Bai, Q. (2010). Subsea engineering handbook. Burlington, USA: Gulf Professional.

Bhowmik, S. (2019). Digital twin of subsea pipelines: conceptual design integrating IOT, machine learning and data analytics. Offshore Technology Conference, 1-9. https://doi.org/10.4043/29455-ms

Chang, C. S., Wang, Z., Yang, F., and Tan, W. W. (2012). Hierarchical fuzzy logic system for implementing maintenance schedules of offshore power systems. IEEE Transactions on Smart Grid, 3(1), 3-11. https://doi.org/10.1109/tsg.2011.2173358

Hwang, C., and Yoon, K. (1981). Multiple attribute decision making: methods and applications a state-of-theart survey. New York, USA: Springer.

Jang, J. R., Sun, C., and Mizutani, E. (1997). Neuro-fuzzy and soft computing: a computational approach to learning and machine intelligence. California, USA: Pearson College.

Kolios, A. J., Umofia, A., and Shafiee, M. (2017). Failure mode and effects analysis using a fuzzy-topsis method: a case study of subsea control module. International Journal of Multicriteria Decision Making, 7(1), 29-53. https://doi.org/10.1504/ijmcdm.2017.085154

Koto, J. (Ed.). (2017). Life cycle cost of subsea production system (2nd ed.). Pekanbaru-Riau, Indonesia: Ocean and Aerospace Research Institute.

Nieto González, J. P., and Villanueva, P. P. (2013). Complete diagnosis of electrical power systems using MDS and ANFIS. Advances in Soft Computing and Its Applications, 8266, 150-161. https://doi.org/10.1007/9783-642-45111-9 13

Shafiee, M. (2015). Maintenance strategy selection problem: a MCDM overview. Journal of Quality in Maintenance Engineering, 21(4), 378-402. https://doi.org/10.1108/jqme-09-2013-0063

Solyali, D. (2020). A comparative analysis of machine learning approaches for short-/long-term electricity load forecasting in Cyprus. Sustainability, 12(9), 3612. https://doi.org/10.3390/su12093612

Ukoba, O.M., Diemuodeke, E.O., Alghassab, M., Njoku, H.I., Imran, M. and Khan, Z.A. (2020) Composite Multi-Criteria Decision Analysis for Optimization of Hybrid Renewable Energy Systems for Geopolitical Zones in Nigeria, Sustainability, 12, 12, 5732. https://doi.org/10.3390/su12145732

Umofia, A. N. (2014). Risk-based reliability assessment of subsea control module for offshore oil and gas production (Thesis, Cranfield University). Retrieved from https://dspace.lib.cranfield.ac.uk/bitstream/handle/1826/9256/Umofia_Anietie_Thesis_2014.pdf?sequence=

Yavuz, M. (2012). Applications of the TOPSIS method to solve some decision making problems in mining operations. Journal of Underground Resources, (2), 21-34. Retrieved from https://dergipark.org.tr/en/download/article-file/366559 